\title{
microRNA-30c negatively regulates endometrial cancer cells by targeting metastasis-associated gene-1
}

\author{
HUAIJUN ZHOU ${ }^{1}$, XIAOFENG XU ${ }^{1}$, QINGYING XUN ${ }^{4}$, DONGQI YU ${ }^{3}$, JINGXIAN LING $^{1}$, \\ FEIFEI GUO ${ }^{3}$, YUHUA YAN ${ }^{3}$, JIAYU SHI ${ }^{3}$ and YALI HU ${ }^{1,2}$ \\ ${ }^{1}$ Department of Obstetrics and Gynecology, Nanjing Drum Tower Hospital, Nanjing University \\ Medical School, Nanjing 210008; ${ }^{2}$ Reproductive Medicine Center, Nanjing Drum Tower Hospital, \\ Nanjing University Medical School, Nanjing 210008; ${ }^{3}$ Medical College, Southeast University, \\ Nanjing 210009; ${ }^{4}$ Department of Physiology, Medical College, \\ Southeast University, Nanjing 210009, P.R. China
}

Received October 12, 2011; Accepted November 14, 2011

DOI: 10.3892/or.2011.1574

\begin{abstract}
It is well known that microRNAs (miRNAs) play important roles in cancer development by targeting oncogenes or tumor-suppressor genes. However, little is known regarding the mechanisms of miR-30c action in endometrial cancer. In this study, we aimed to determine whether miR-30c targets metastasis-associated gene-1 (MTA1) and acts as a tumor suppressor in endometrial cancer cell lines Ishikawa (estrogen receptor-positive, $\mathrm{ER}^{+}$) and $\mathrm{HEC}-1-\mathrm{B}$ (ER) by down-regulating MTA1. As a result, in both Ishikawa and HEC-1-B cells, realtime PCR demonstrated that overexpression of miR-30c led to the down-regulation of MTA1 mRNA $(\mathrm{P}<0.05)$, while Western blotting confirmed the reduced expression levels of MTA1 protein $(\mathrm{P}<0.01)$. A dual-luciferase reporter assay demonstrated that miR-30c was directly bound to the 3'-untranslated regions of MTA1. Then we studied the biological mechanisms of endometrial cancer cells transfected with the Pre-miR-30c plasmid. MTT assay and growth curves revealed that miR-30c inhibits both Ishikawa and HEC-1-B cell proliferation. However, we did not see obvious differences in rates of apoptosis between miR30c-overexpressing and the negative control cells. Then using wound-healing and Matrigel invasion assays, we found that the migratory and invasive abilities of cells transfected with the
\end{abstract}

Correspondence to: Dr Yali Hu, Department of Obstetrics and Gynecology, Nanjing Drum Tower Hospital, Nanjing University Medical School, Nanjing 210008, P.R. China

E-mail: dtylhu@126.com

Abbreviations: miRNA, microRNA; MTA1, metastasis-associated gene-1; ER, estrogen receptor; 3'-UTR, 3'-untranslated regions; PAI1, plasminogen activator inhibitor-1

Key words: miR-30c, endometrial cancer, metastasis-associated gene-1, HEC-1-B cells, Ishikawa cells
Pre-miR-30c plasmid were significantly suppressed compared with the control cells $(\mathrm{P}<0.01)$. Overall, our study, for the first time, showed that MTA1 is negatively regulated by miR-30c and that overexpression of miR-30c inhibits the proliferative, migratory and invasive abilities of endometrial cancer cells. These results suggest that miR-30c acts as a tumor suppressor and negatively regulates endometrial cancer cells by targeting MTA1.

\section{Introduction}

Endometrial carcinoma is a common worldwide gynecologic malignancy. Two different clinicopathological subtypes of endometrial cancer are recognized: one is estrogen-related type 1 (endometroid), and the other is non-estrogen-related type 2 (non-endometroid such as papillary serous and clear cell) (1). Although various endocrine, genetic and external factors, such as unopposed estrogen exposure, complex hyperplasia with atypia, and treatment with tamoxifen during breast cancer therapy, may contribute to its initiation and progression, the etiology of endometrial carcinoma remains not fully understood (2). The primary and most effective treatment for patients with localized disease is still hysterectomy and bilateral salpingo-oophorectomy (3). Although adjuvant radiotherapy and chemotherapy may reduce local recurrence and systemic metastases, the associated toxicity and morbidity are significant (4). Thus, the search for novel molecular targets as therapeutic agents through an increased understanding of the molecular mechanisms of endometrial tumorigenesis is in urgent need.

microRNAs (miRNAs) are a class of conserved short (19-25 nt) RNAs that regulate gene expression through basepairing with the 3'-untranslated regions (3'-UTR) of target mRNAs (5) and play an important role in various biological processes (6-8). Accumulating evidence suggests that dysregulation of certain miRNAs may lead to the development of cancer $(9,10)$. While many oncogenic miRNAs, including miR-184, miR-95 and miR-27a, are overexpressed in tumors (11-13), some tumor-suppressive miRNAs are down-regulated. 
Particularly, the loss of expression of miR-30c occurs in many types of malignancies, including endometrial cancer (14-16). miR-30c has been proposed to impact human pulmonary endothelial cells through targeting the 3'-UTR of plasminogen activator inhibitor-1 (PAI1) (17).

Metastasis-associated gene-1 (MTA1) is widely up-regulated in many carcinomas and its expression correlates with the clinicopathological characteristics (malignant properties) of human cancers $(17,18)$. A previous study demonstrated that miR-661 regulates cell functions by targeting the 3'-UTR of MTA1 (20). In this report, we provide evidence concerning the molecular mechanism by which miR-30c produces negative effects on endometrial cancer cells, considering that MTA1 is a possible target of miR-30c.

\section{Materials and methods}

Cell culture. Human endometrial cancer cell lines Ishikawa and HEC-1-B were kindly provided by Professor L.H. Wei (Peking University People's Hospital, China) and cultured in Dulbecco's modified Eagle's medium (DMEM, Gibco, USA) supplemented with $10 \%$ fetal bovine serum (FBS, Gibco) and penicillin $(100 \mathrm{U} / \mathrm{ml})$. Cultures were maintained in a $5 \% \mathrm{CO}_{2}$ humidified atmosphere at $37^{\circ} \mathrm{C}$. Cells were passaged to maintain normal growth every 3 days.

Plasmid construction and cell transfection. The candidate pri-miRNA-30c of double-stranded oligonucleotides (523 bp) was generated for cloning into the vector pRNAT-CMV3.2Neo (GenScript, China). The plasmid was sequenced and named pRNAT-CMV3.2-Neo-miR-30c (Pre-miR-30c), compared with the empty pRNAT-CMV3.2-Neo vector (negative control, NC). Cell transfection was performed with Lipofectamine 2000 (Invitrogen, USA) according to the manufacturer's instructions. After $2 \mathrm{~h}$ of starvation in serumfree medium, the cells plated in 6-well plates were transfected with $8 \mu \mathrm{l}$ of Lipofectamine reagent containing $4 \mu \mathrm{g}$ of plasmid DNA. G418 (400 $\mu \mathrm{g} / \mathrm{ml}$, Gibco) was added to the medium $24 \mathrm{~h}$ after transfection. Cells were screened and cultured for an additional 4 weeks.

qRT-PCR analysis of miRNA-30c and MTA1 mRNA expression. Total RNA was isolated using TRIzol reagent (Invitrogen) and then both miRNA and mRNA were reversetranscribed to cDNA with the Reverse Transcriptase M-MLV kit (Takara, China). The stem-loop RT primer for miR-30c was 5'-GTCGTATCCAGTGCAGGGTCCGAGTATTCGC ACTGGATACGACGCTGA-3' (14). U6 small nuclear RNA was used as an internal control.PCR reactions were performed with the SYBR PrimeScript RT-PCR kit (Takara) and the following primers: for hsa-miR-30c, forward, 5'-GCCGCTG TAAACATCCTACACT-3' and reverse, 5'-GTGCAGGGTCC GAGGT-3'; and for U6, forward, 5'-CTCGCTTCGGCA GCACA-3' and reverse, 5'-AACGCTTCACGAATTTGCGT-3'. Relative levels of MTA1-mRNA were examined also by SYBR-Green real-time PCR (qRT-PCR) and normalized to $\beta$-actin mRNA. The relative primers for MTA1 were forward, 5'-AGCTACGAGCAGCACAACGGGGT-3' and reverse, 5'-CACGCTTGGTTTCCGAGGAT-3'; and for $\beta$-actin, forward, 5'-CGTGGGCCGCCCTAGGCACCA-3' and reverse, 5'-TTGGCTTAGGGTTCAGGGGGG-3'. The SYBRGreen qPCR was performed using the ABI 7500 Fast Real-Time PCR system, and changes in expression were calculated using the ${ }^{\Delta \Delta} \mathrm{Ct}$ method (21), and each plate was run in triplicate.

Western blot analysis. Total proteins were prepared from transfected Ishikawa or HEC-1-B cells using radioimmunoprecipitation assay (RIPA) lysis buffer (Sigma, USA) supplemented with protease inhibitors. An equal amount $(50 \mu \mathrm{g})$ of cellular lysates was electrophoresed on $10 \%$ SDS-polyacrylamide gel electrophoresis (PAGE) minigels and transferred onto polyvinylidene fluoride (PVDF) membranes (Millipore, USA). After incubation with the primary antibodies (1:1,000; Abcam, Cambridge, $\mathrm{UK})$ at $4^{\circ} \mathrm{C}$ overnight, the membranes were washed with Tris-buffered saline Tween-20 (TBST) and then incubated with a secondary antibody conjugated to peroxidase $(1: 10,000$; Bioworld Technology, USA) for $2 \mathrm{~h}$. After extensive washes, the membranes were visualized using an ECL chemiluminescence (Millipore). GAPDH was used for normalization. The relative intensity of the target bands was analyzed by Quantity One. Each assay was repeated twice.

Luciferase reporter assay. The predicted target gene of miR-30c was retrieved using a publicly available database (TargetScan, www.targetscan.org). We synthesized the 3'-UTR of MTA1 which were $280 \mathrm{nt}$ long and contained the predicted binding sites for miR-30c. The control sequences containing several mutated bases within the binding sites were also synthesized. The corresponding genes were then cloned into the pGL3-promoter vector. Ishikawa and HEC-1-B cells were plated at $1 \times 10^{5}$ in 12 -well format. After $24 \mathrm{~h}$, the pGL3 reporters containing the MTA1 binding site for miR-30c or the mutated MTA1 binding site were co-transfected with either the Pre-miR-30c plasmid or the negative control using Lipofectamine 2000. The Renilla luciferase was used to normalize the cell number and the transfection efficiency. Luciferase activity was measured by the Dual Luciferase assay (Promega, USA) according to the manufacturer's instructions after $48 \mathrm{~h}$ on the Luminometer (Promega). Each assay was repeated 3 times.

MTT assay and growth curves. Ishikawa and HEC-1-B cells transfected with either the Pre-miR-30c plasmid or the negative control were plated on 96 -well plates at $5 \times 10^{3}$ cells/well. Viable cells were evaluated 1,2,3, and 4 days after plating. After incubation with $20 \mu \mathrm{l}$ of 3-(4,5-dimethylthiazolyl-2)-2, 5-diphenyltetrazolium bromide (MTT, $5 \mathrm{mg} / \mathrm{ml}$; Sigma, USA) solution at $37^{\circ} \mathrm{C}$ for $4 \mathrm{~h}$, the cells were lysed in $150 \mu \mathrm{l}$ of dimethyl sulfoxide (DMSO), and the absorbance values of blue formazan were determined at $570 \mathrm{~nm}$ with a microplate reader. For growth curves, approximate numbers $\left(3 \times 10^{4}\right.$ for Ishikawa, and $5 \times 10^{4}$ for HEC-1-B) of cells were plated into 24-well plates. The cells were harvested and counted from the next day after seeding.

Apoptosis assay. Apoptosis was assessed with Annexin V/ $\mathrm{PE}$ and 7-aminoactinomycin (7-AAD) staining with the Annexin V/PE Apoptosis Detection kit (BD Pharmingen, USA). 

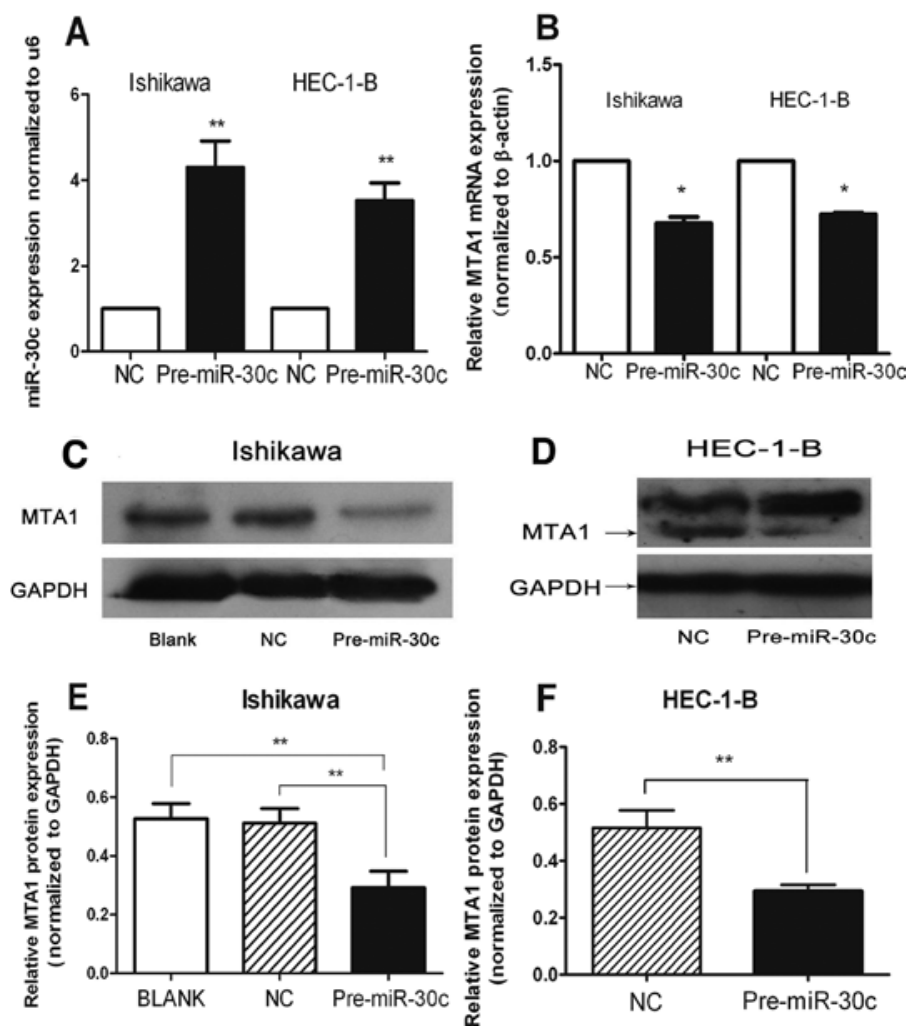

Figure 1. miR-30c overexpression decreases MTA1 production in human endometrial cancer cells. (A) Ishikawa and HEC-1-B cells were transfected with Pre-miR-30c or the appropriate control plasmid. Total RNA was isolated and analyzed for miR-30c expression by real-time PCR. (B) Relative MTA1 mRNA expression was analyzed by real-time PCR as in A. (C and D) Western blot analysis of MTA1 protein expression in the two endometrial cancer cell lines following miR-30c overexpression as performed in A. (E and F) Quantification of the relative MTA1 protein expression in Ishikawa and HEC-1-B cells following miR-30c overexpression as performed in $\mathrm{A} .{ }^{*} \mathrm{P}<0.05,{ }^{* *} \mathrm{P}<0.01$.

After cells $\left(1 \times 10^{6}\right)$ were transfected with the Pre-miR-30c/NC plasmid for $48 \mathrm{~h}$, they were washed in cold PBS buffer twice and then re-suspended in $100 \mu$ l binding buffer. Annexin V-PE $(5 \mu \mathrm{l})$ and 7-AAD $(5 \mu \mathrm{l})$ were used for staining cells $\left(1 \times 10^{5}\right)$ by incubating for $15 \mathrm{~min}$ in the dark. Following this, results were acquired by flow cytometry (FACSCalibur, Becton Dickinson) and analyzed using BD FACSDiva Software. Each assay was repeated 3 times.

In vitro invasion assays. For the migration assay, Ishikawa and HEC-1-B cells were transfected with Pre-miR-30c or control, cultured for $48 \mathrm{~h}$, and transferred onto the top of Matrigelcoated invasion chambers (24-well insert, $8-\mu \mathrm{m}$ pore size; Millipore) in serum-free DMEM at $1 \times 10^{5}$ cells $/ \mathrm{ml}$. DMEM containing $10 \%$ FBS was added as the chemoattractant to the lower chamber. After $24 \mathrm{~h}$ of incubation, cells on the upper surface were gently removed from the inner part of the insert with a cotton swab. The cells that invaded the Matrigel and attached to the lower surface were fixed and stained with $0.1 \%$ crystal violet. Cells were counted in 5 randomly high power fields at X200 magnification in each well. The experiment was repeated twice.

Wound-healing assay. Transfected cells were seeded in 6-well plates and cultured in DMEM with 10\% FBS. When grown to confluence, cells were wounded by dragging a $10-\mu 1$ pipette tip through the monolayer. The cells were cultured without FBS for another $24 \mathrm{~h}$ migration. The individual gaps were observed and photographed under an inverted microscope. We performed each assay for 3 replicates.

Statistical analysis. Statistical analyses were performed using SPSS 17.0 software. All values are expressed as mean \pm SEM. Differences between groups were analyzed by the unpaired Student's t-test. Statistical significance was accepted for P-values $<0.05$.

\section{Results}

miR-30c overexpression decreases MTAl production in human endometrial cancer cells. pRNAT-CMV3.2-NeomiR-30c and negative control plasmids were transfected into human endometrial cancer Ishikawa and HEC-1-B cells. The SYBR-Green real-time PCR revealed that transfection of the Pre-miR-30c plasmid caused a 4.3-fold (for Ishikawa) and 3.5-fold (for HEC-1-B) increase in miR-30c expression compared to the negative control (Fig. $1 \mathrm{~A} ; \mathrm{P}<0.01$ ). Using quantitative RT-PCR and Western blotting, we confirmed the down-regulation of MTA1 at both the mRNA and protein levels in Ishikawa/Pre-miR-30c or HEC-1-B/Pre-miR-30c cells when compared with the control group. While the MTA1 mRNA expression was decreased by $33 \%$ (for Ishikawa) and $28 \%$ (for HEC-1-B) (Fig. 1B; P $<0.05$ ), the MTA1 protein expression was suppressed by $\sim 49 \%$ (for Ishikawa) (Fig. 1E; $\mathrm{P}<0.01$ ) and $40 \%$ (for HEC-1-B) (Fig. 1F; $\mathrm{P}<0.01$ ) at $48 \mathrm{~h}$ after transfection with the Pre-miR-30c plasmid. 

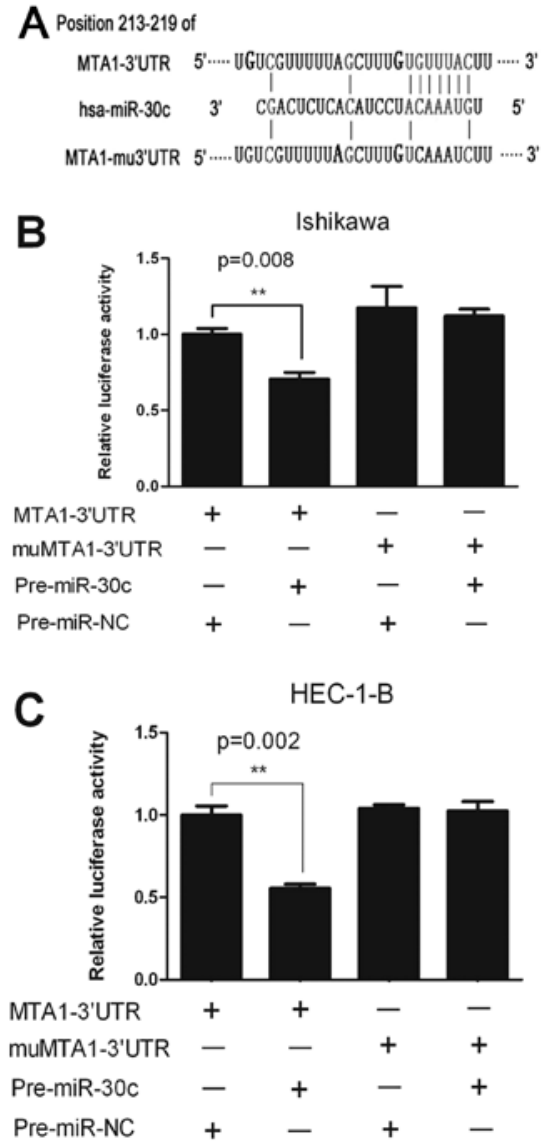

Figure 2. miR-30c targets 3'-UTR of MTA1. (A) Sequences of the 3'-UTR region of MTA1 containing miR-30c binding sites. The corresponding mutated sequences are shown as well. The synthesized DNA was subsequently cloned into a Luciferase reporter pGL3-promoter plasmid. (B and C) The impact of miR-30c overexpression on pGL3-MTA1 luciferase activity in Ishikawa and HEC-1-B cells is shown. Data represent two independent experiments performed in triplicate. ${ }^{* *} \mathrm{P}<0.01$.
miR-30c targets 3'-UTR of MTA1. We next investigated whether the 3'-UTR of MTA1 is a functional target of miR-30c. We cloned the 3'-UTR sequences of MTA1 into the reporter plasmid PGL3. Fig. 2A shows the sequences of the 3'-UTR of MTA1 that represents the binding sites of miR-30c. The corresponding mutated sequences of the 3'-UTR of MTA1 are shown as well. Loss of luciferase activity was observed in neither Ishikawa cells nor HEC-1-B cells transfected with Pre-miR-30c and mutated 3'-UTR of MTA1. Yet nearly a $30 \%$ reduction in luciferase activity was observed with wildtype MTA1 in Ishikawa cells (Fig. $2 \mathrm{~B} ; \mathrm{P}<0.01$ ) and $45 \%$ in HEC-1-B cells (Fig. 2C; $\mathrm{P}<0.01$ ) which were transfected with Pre-miR-30c. These data support that MTA1 is a direct target of miR-30c.

miR-30c inhibits cell growth but does not induce apoptosis in vitro. We used the MTT assay to detect the effect of miR-30c on cell proliferation. The MTT proliferation assay indicated that from the third day after plating, the cell survival of Pre-miR-30c transfected Ishikawa and HEC-1-B cells was significantly less than the negative control (Fig. $3 \mathrm{~A} ; \mathrm{P}<0.05$ ). To provide further evidence that miR-30c inhibits cell proliferation, growth curves were constructed by counting the cell numbers (Fig. 3B; $\mathrm{P}<0.05$ and $\mathrm{P}<0.01$ ). These data showed that miR-30c indeed suppressed endometrial cancer cell growth. To determine whether miR-30c induces cell apoptosis, we performed an apoptosis assay. Out of our expectation, the apoptosis rates were not obviously different between the miR30c-overexpressed and negative control cells both for Ishikawa and HEC-1-B cells (data not shown).

miR-30c influences cell migration and invasion of endometrial cancer lines. To evaluate the impact of miR-30c on cell migration, a wound-healing assay was performed. As shown in Fig. 4A, the migration significantly decreased in Ishikawa
A

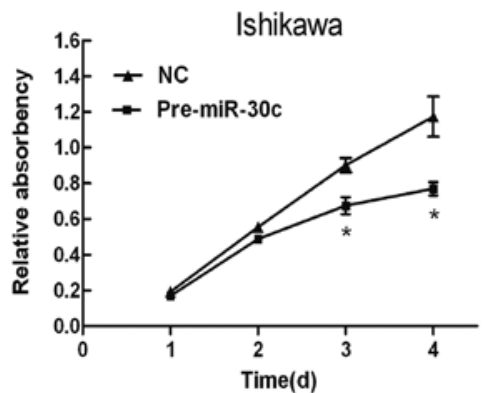

B

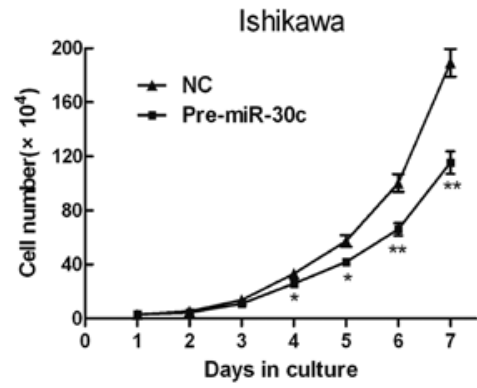

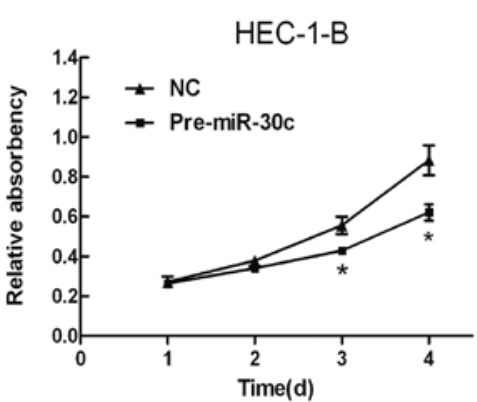

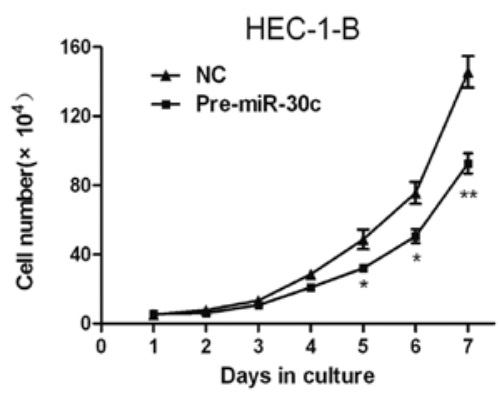

Figure 3. miR-30c inhibits cell growth. (A) MTT proliferation in Ishikawa (left) and HEC-1-B (right) cells. (B) Growth curves were constructed by counting the cell numbers in Ishikawa (left) and HEC-1-B (right) cells. All results were reproducible in 3 independent experiments. ${ }^{*} \mathrm{P}<0.05,{ }^{* *} \mathrm{P}<0.01$. 


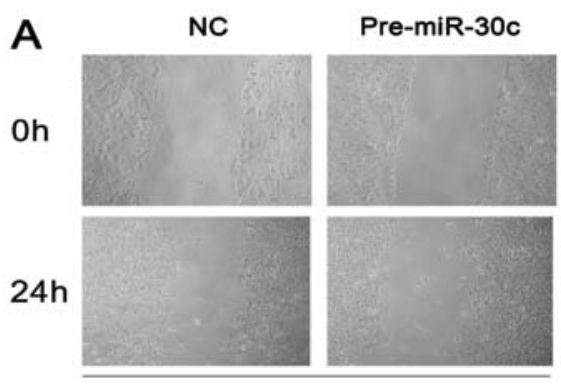

Ishikawa

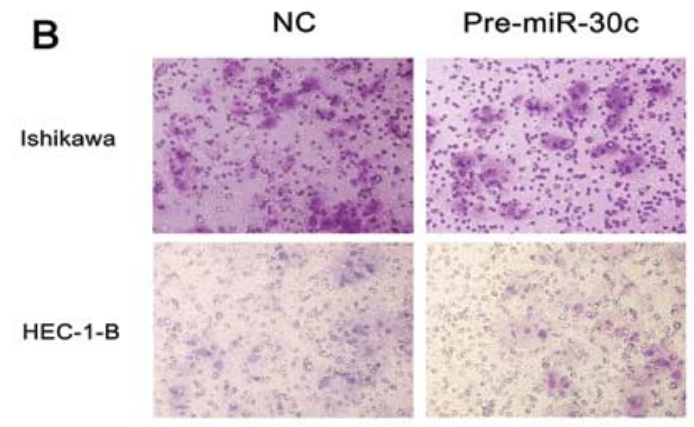

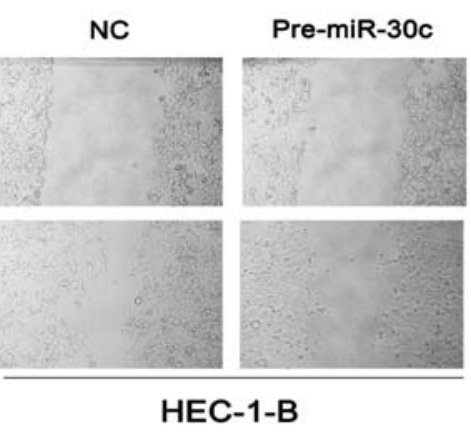

C

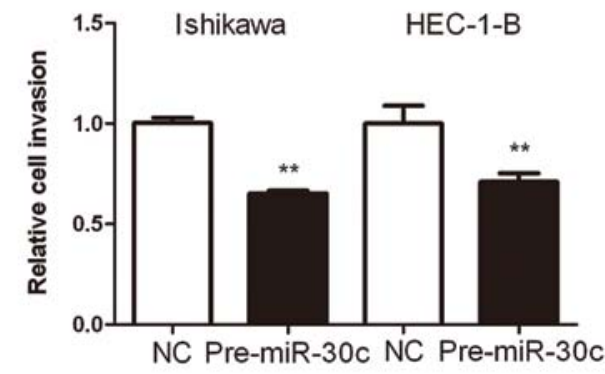

Figure 4. miR-30c influences cell migration and invasion of endometrial cancer cell lines. (A) Representative images of the wound-healing assay show the occlusion of the artificial wound performed in the post-transfected cells $24 \mathrm{~h}$ after wounding. (B and C) Transwell invasion assay demonstrates the suppressed invasive ability of cells $48 \mathrm{~h}$ post-transfection. The average number of cells was counted from 5 random microscopic fields (x200). Each independent experiment was performed twice $\left({ }^{* *} \mathrm{P}<0.01\right)$.

and HEC-1-B cells transfected with Pre-miR-30c. We also employed a Matrigel invasion assay to determine the relative invasive ability of endometrial cancer cells. Cell invasive ability was markedly weakened after transfection with Pre-miR-30c. Compared to the negative control, miR-30c overexpression resulted in a $35 \%$ (for Ishikawa) or $29 \%$ (for HEC-1-B) reduction in cell invasion (Fig. 4B and $\mathrm{C} ; \mathrm{P}<0.01$ ). Taken together, the results revealed that overexpression of miR-30c inhibits the migratory and invasive abilities of endometrial cancer cells.

\section{Discussion}

Recently, many studies have focused on understanding the roles of miR-30c in cancer. Although non-differential expression of miR-30c was observed in cervical cancer cell lines (22) and nasopharyngeal carcinoma tissues (23) compared to the normal controls, most studies have suggested that miR-30c acts as a tumor suppressor and is weakly expressed in cancers such as breast cancer (24), bladder cancer (14), medulloblastoma (15) and clear-cell renal cell carcinoma (25), depending on the tissue context. In this report, we demonstrated the antitumor role of miR-30c in endometrial cancer cells.

Rapid cell growth is a distinctive feature of cancer, and cell invasion is one of the essential events in cancer metastasis. Previously, many miRNAs have been reported to play negative roles in cancer cell proliferation $(26,27)$ migration and invasion $(28,29)$. Considering the two different clinicopathological subtypes of endometrial cancer, here we used two different cells: Ishikawa is a ER-positive endometrial cancer cell line, while HEC-1-B is a ER-negative endometrial cancer cell line
(30). For the first time, we showed the consistent biological behavior of Ishikawa and HEC-1-B cells after overexpression of miR-30c. This indicates that this miRNA may suppress cell growth, migration and invasion in both ER-positive and ER-negative endometrial cancer cells. Thus, we speculate that miR-30c may act as a tumor suppressor in endometrial cancer, in view of the low expression of miR-30c in endometrial cancer specimens compared to normal controls (16).

Our study showed that overexpression of miR-30c leads to the down-regulation of MTA1 both at the mRNA and protein levels. Moreover, enhanced $\mathrm{miR}-30 \mathrm{c}$ reduced the luciferase activity in cells transfected with the PGL3 plasmid containing the predicted 3'-UTR binding sites for miR-30c. Therefore, we confirmed that MTA1 is one of the targets of miR-30c. MTA1 is involved in the NuRD complex and functions in histone deacetylation (19). Experimental inhibition of its protein expression can inhibit cell invasion and proliferation (31) and enhance the expression of tumor suppressor genes like P53 (32) and BRCA1 (33). MTA1 represents master co-regulatory molecules involved in the carcinogenesis and progression of various malignant tumors (30). Considering that MTA1 is also overexpressed in endometrial cancer (34), it is logical to believe that miR-30c acts as a tumor suppressor in endometrial carcinoma. Together, miR-30c suppresses cell proliferation and invasion partly by reversely regulating MTA1 expression. To note, the MTA1 level as regulated by miR-661 can also impassion the biological mechanism of breast cancer cells (20). More recently, there has been growing interest in the field of miRNAs as biomarkers of cancer risk, diagnosis and response to therapy (35). However, little is known regarding 
the relationship between miR-30c and clinical endometrial carcinoma. Our study suggests that overexpression of miR-30c alone or in conjunction with other antitumor treatments may represent a novel effective therapeutic intervention to prevent progression of endometrial cancer in the future.

\section{Acknowledgements}

This study was supported by Grant H200942 awarded by the Health Department of Jiangsu Province, China. The authors acknowledge Professor Zhenyu Diao and Guijun Yan, Reproductive Medicine Center, Nanjing Drum Tower Hospital, Nanjing University Medical School, Nanjing, China, for their critical experimental suggestions.

\section{References}

1. Mueck AO, Seeger H and Rabe T: Hormonal contraception and risk of endometrial cancer: a systematic review. Endocr Relat Cancer 17: R263-R271, 2010

2. Di Cristofano A and Ellenson LH: Endometrial carcinoma. Annu Rev Pathol 2: 57-85, 2007.

3. Myatt SS, Wang J, Monteiro LJ, et al: Definition of microRNAs that repress expression of the tumor suppressor gene FOXO1 in endometrial cancer. Cancer Res 70: 367-377, 2010.

4. Ray M and Fleming G: Management of advanced-stage and recurrent endometrial cancer. Semin Oncol 36: 145-154, 2009.

5. Ambros V: The functions of animal microRNAs. Nature 431: 350-355, 2004

6. Bartel DP: MicroRNAs: Genomics, biogenesis, mechanism, and function. Cell 116: 281-297, 2004.

7. Du T and Zamore PD: microPrimer: The biogenesis and function of microRNA. Development 132: 4645-4652, 2005.

8. Park SM and Peter ME: microRNAs and death receptors. Cytokine Growth Factor Rev 19: 303-311, 2008.

9. Croce $\mathrm{CM}$ and Calin GA: miRNAs, cancer, and stem cell division. Cell 122: 6-7, 2005.

10. Esquela-Kerscher A and Slack FJ: Oncomirs - microRNAs with a role in cancer. Nat Rev Cancer 6: 259-269, 2006.

11. Wong TS, Liu XB, Wong BY, Ng RW, Yuen AP and Wei WI: Mature miR-184 as potential oncogenic microRNA of squamous cell carcinoma of tongue. Clin Cancer Res 14: 2588-2592, 2008 .

12. Huang Z, Huang S, Wang Q, et al: MicroRNA-95 promotes cell proliferation and targets sorting nexin 1 in human colorectal carcinoma. Cancer Res 71: 2582-2589, 2011.

13. Mertens-Talcott SU, Chintharlapalli S, Li X and Safe S: The oncogenic microRNA-27a targets genes that regulate specificity protein transcription factors and the G2-M checkpoint in MDA-MB-231 breast cancer cells. Cancer Res 67: 11001-11011, 2007.

14. Wang G, Zhang $\mathrm{H}, \mathrm{He} \mathrm{H}$, et al: Up-regulation of microRNA in bladder tumor tissue is not common. Int Urol Nephrol 42: 95-102, 2010.

15. Ferretti E, De Smaele E, Po A, et al: MicroRNA profiling in human medulloblastoma. Int J Cancer 124: 568-577, 2009.

16. Boren T, Xiong Y, Hakam A, et al: MicroRNAs and their target messenger RNAs associated with endometrial carcinogenesis. Gynecol Oncol 110: 206-215, 2008.
17. Patel N, Tahara SM, Malik P and Kalra VK: Involvement of miR-30c and miR-301a in immediate induction of plasminogen activator inhibitor-1 by placental growth factor in human pulmonary endothelial cells. Biochem J 434: 473-482, 2011.

18. Manavathi B, Singh K and Kumar R: MTA family of coregulators in nuclear receptor biology and pathology. Nucl Recept Signal 5: e010, 2007.

19. Toh Y and Nicolson GL: The role of the MTA family and their encoded proteins in human cancers: molecular functions and clinical implications. Clin Exp Metastasis 26: 215-227, 2009.

20. Reddy SD, Pakala SB, Ohshiro K, Rayala SK and Kumar R: MicroRNA-661, a c/EBPalpha target, inhibits metastatic tumor antigen 1 and regulates its functions. Cancer Res 69: 5639-5642, 2009.

21. Livak KJ and Schmittgen TD: Analysis of relative gene expression data using real-time quantitative PCR and the 2(-Delta Delta C(T)) method. Methods 25: 402-408, 2001.

22. Lui WO, Pourmand N, Patterson BK, et al: Patterns of known and novel small RNAs in human cervical cancer. Cancer Res 67: 6031-6043, 2007

23. Li T, Chen JX, Fu XP, et al: microRNA expression profiling of nasopharyngeal carcinoma. Oncol Rep 25: 1353-1363, 2011.

24. Shen J, Ambrosone CB and Zhao H: Novel genetic variants in microRNA genes and familial breast cancer. Int J Cancer 124: $1178-1182,2009$.

25. Heinzelmann J, Henning B, Sanjmyatav J, et al: Specific miRNA signatures are associated with metastasis and poor prognosis in clear cell renal cell carcinoma. World J Urol 29: 367-373, 2011.

26. Song YX, Yue ZY, Wang ZN, et al: MicroRNA-148b is frequently down-regulated in gastric cancer and acts as a tumor suppressor by inhibiting cell proliferation. Mol Cancer 10: 1, 2011.

27. Chen Z, Zeng H, Guo Y, et al: miRNA-145 inhibits non-small cell lung cancer cell proliferation by targeting c-Myc. J Exp Clin Cancer Res 29: 151, 2010.

28. Wu L, Cai C, Wang X, Liu M, Li X and Tang H: MicroRNA-142-3p, a new regulator of $\mathrm{RAC1}$, suppresses the migration and invasion of hepatocellular carcinoma cells. FEBS Lett 585: 1322-1330, 2011.

29. Viticchie G, Lena AM, Latina A, et al: MiR-203 controls proliferation, migration and invasive potential of prostate cancer cell lines. Cell Cycle 10: 1121-1131, 2011.

30. Bamberger AM, Bamberger CM, Gellersen B and Schulte HM: Modulation of AP-1 activity by the human progesterone receptor in endometrial adenocarcinoma cells. Proc Natl Acad Sci USA 93: 6169-6174, 1996.

31. Nicolson GL, Nawa A, Toh Y, Taniguchi S, Nishimori K and Moustafa A: Tumor metastasis-associated human MTA1 gene and its MTA1 protein product: role in epithelial cancer cell invasion, proliferation and nuclear regulation. Clin Exp Metastasis 20: 19-24, 2003.

32. Moon HE, Cheon H and Lee MS: Metastasis-associated protein 1 inhibits p53-induced apoptosis. Oncol Rep 18: 1311-1314, 2007.

33. Molli PR, Singh RR, Lee SW and Kumar R: MTA1-mediated transcriptional repression of BRCA1 tumor suppressor gene. Oncogene 27: 1971-1980, 2008.

34. Balasenthil S, Broaddus RR and Kumar R: Expression of metastasis-associated protein 1 (MTA1) in benign endometrium and endometrial adenocarcinomas. Hum Pathol 37: 656-661, 2006.

35. Chan E, Prado DE and Weidhaas JB: Cancer microRNAs: From subtype profiling to predictors of response to therapy. Trends Mol Med 17: 235-243, 2011. 